\title{
PROCESSOS CULTURAIS E CADEIA PRODUTIVA DO ARTESANATO: UMA ANÁLISE SOBRE A CERÂMICA DO CABO DE SANTO AGOSTINHO/PE, BRASIL.
}

\author{
Tibério Tabosa \\ Universidade Federal de Pernambuco \\ tiberio.tabosa@oimaginario.com.br \\ Virgínia Cavalcanti \\ Universidade Federal de Pernambuco \\ virginia.cavalcanti@oimaginario.com.br \\ Erimar Cordeiro \\ Universidade Federal de Pernambuco \\ erimar.cordeiro@oimaginario.com.br \\ Ana Maria Andrade \\ Universidade Federal de Pernambuco \\ ana.andrade@oimaginario.com.br
}

Resumo: O artigo apresenta o resultado do projeto de pesquisa intitulado "Modelo de análise da cadeia produtiva do artesanato", realizado em três fases e viabilizado por editais do Funcultura - PE. Tem como objetivo construir um modelo de análise da cadeia produtiva do artesanato, dentro da visão da economia criativa, a partir dos referenciais de um conjunto de comunidades produtoras artesanais com renome e nível de maturação reconhecidos que apresentam características diversas em termos das tipologias trabalhadas, organização da produção, origem das matériasprimas e apoios recebidos, considerando parâmetros de sustentabilidade, visando a agregação de valor e nível de consumo dos produtos que possibilitem a melhoria da qualidade de vida dos artesãos. A metodologia de abordagem adotada foi a Dialética (Demo, 1995) utilizando o método comparativo (Gil, 1987) e o estudo de caso (Yin, 2005), conduzida pela motivação da cadeia de valor e design (Krucken, 2012) e contextualizada no campo da Economia Criativa (Howkins, 2001).

Palavras chaves: artesanato, cadeia produtiva, processos culturais.

The paper presents the results of the research project entitled "Analysis model for the craft production chain", made possible by public notice of Funcultura-PE. The Project aims at building an analytical model for the craft production chain, within the creative economy view, using as references a set of craft producing communities with renowned and recognized maturation level that have distinct characteristics in terms of worked 
typologies, organization of production, origin of raw materials and support received, taking into account sustainability parameters with the intention to add value and level of consumption of products that enable the improvement of the quality of life of craftsmen. The approach methodology adopted was the Dialectic (Demo, 1995) using the comparative method (Gil, 1987) and the case study (Yin, 2005), driven by motivation value chain and design (Krucken, 2012) and contextualized in the field of Creative Economy (Howkins, 2001).

Keywords: craft, production chain, cultural processes

\section{INTRODUÇÃO}

O artigo apresenta o resultado do projeto de pesquisa intitulado "Modelo de análise da cadeia produtiva do artesanato" aprovado pelo Sistema de Incentivo à Cultura (SIC) do Governo do Estado de Pernambuco - Edital Funcultura Independente 2011/2012 - Área: Artesanato; Subárea: Pesquisa, através da Fundação do Patrimônio Histórico e Artístico de Pernambuco (Fundarpe)

O contexto da pesquisa foi o estado de Pernambuco, localizado no Nordeste brasileiro, região na qual a evolução da indústria de bens de consumo tem ocorrido de forma mais lenta do que em outras regiões do país, contribuindo para a existência de uma grande população para a qual as únicas opções de geração de trabalho e renda permanecem atreladas ao exercício de atividades manuais e/ou artesanais. Desse modo, gerações inteiras se sucedem repetindo praticas produtivas de grande riqueza cultural, mas com baixíssimo nível de inserção no mercado consumidor e sem quase nenhum grau de sustentabilidade. Nesse sentido, todo esforço até agora feito pelos diversos projetos de intervenção governamental e direcionado ao artesanato ${ }^{1}$ na tentativa de equilibrar o tripé valor cultural $X$ valor econômico $X$ valor social $d a$ produção é um desafio a ser superado.

A lógica da cadeia produtiva do artesanato é uma incógnita para os diversos agentes participantes, incluindo desde artesãos, órgãos governamentais e não governamentais, intermediários, formadores de opinião, consumidores atuais e potenciais etc. Sem a construção de um modelo de análise da cadeia produtiva do artesanato, todo o esforço empregado acaba por não obter os resultados almejados, a sustentabilidade econômica, cultural, social e ambiental dos grupos produtivos.

Nessa diretriz, o projeto de pesquisa teve como objetivo construir um modelo de análise da cadeia produtiva do artesanato, dentro da visão da Economia Criativa², a

\footnotetext{
1 "Produtos artesanais são aqueles confeccionados por artesãos, seja totalmente a mão, com o uso de ferramentas ou até mesmo por meios mecânicos, desde que a contribuição direta manual do artesão permaneça como o componente mais substancial do produto acabado. Essas peças são produzidas sem restrição em termos de quantidade e com o uso de matérias- primas de recursos sustentáveis. A natureza especial dos produtos artesanais deriva de suas características distintas, que podem ser utilitárias, estéticas, artísticas, criativas, de caráter cultural e simbólicas e significativas do ponto de vista social" (UNESCO, 1999).
}

\footnotetext{
${ }^{2}$ A economia criativa foi definida por Howkins (2001) em seu livro seminal The Creative Economy como a economia que abrange os ciclos de criação, produção e distribuição de bens e serviços que usam a criatividade com insumo primário.
} 
partir do dos referenciais de um conjunto de seis comunidades produtoras artesanais que apresentam características diversas em termos das tipologias trabalhadas, organização da produção, origem das matérias-primas e apoios recebidos, considerando parâmetros de sustentabilidade econômica, social, ambiental e cultural visando a agregação de valor e nível de consumo dos produtos que possibilitem a melhoria da qualidade de vida dos artesãos.

O modelo de análise da cadeia produtiva proposto se insere no campo da Economia Criativa (HOWKINS, 2001), conduzido pela motivação da cadeia de valor e design (KRUCKEN, 2009) e desenvolvido com base na metodologia descrita no item 2.1, na experiência dos especialistas e na contribuição dos artesãos das comunidades produtivas envolvidas ao longo dos três anos do projeto.

\section{DESENVOLVIMENTO}

Para a formulação das diretrizes e elaboração do modelo de análise da cadeia produtiva do artesanato, foram definidos: elementos a serem considerados, a sistematização da experiência e a validação e avaliação dos resultados junto às comunidades produtoras. O projeto de pesquisa foi desenvolvido durante três anos, cada ano correspondeu a um contexto específico visando a cobertura das diferentes possibilidades de cadeias produtivas artesanais no estado de Pernambuco; e que pela sua riqueza e diversidade representa o que se observa no restante do país. As fases da investigação são descritas a seguir:

Fase 1 - 2013 | Grupos produtivos considerados: Artesanato Cana-brava Pontas de Pedra/Goiana e Centro de Artesanato Cerâmico Arq. Wilson Campos Junior - Cabo de Santo Agostinho. Estes grupos têm como características: uso de matériasprimas naturais, que são a fibra de cana-brava e argila; foram premiados pelo Top100 SEBRAE de Artesanato e são apoiados pelo Laboratório O Imaginário. Nesta primeira fase, houve a definição do Modelo Básico de Pesquisa baseado nos protocolos (Identificação de Matérias-primas, Processos Produtivos e Acesso a Mercado)

Fase 2-2014 | Grupos produtivos investigados: Tapeçaria Timbi - Camaragibe e AMAM - Associação Mista dos Artesãos de Macaparana - Macaparana. Estas comunidades produtivas tem as características de: empregar matérias-primas industriais - fios de lã e cordões de algodão e fios de algodão; receberam premiação do Top100 SEBRAE de Artesanato e Ponto de Cultura do MinC e receberam suporte do Centro Pernambucano de Design. Esta fase da pesquisa foi marcada pela ampliação dos protocolos no Modelo de Pesquisa, com agregação do item Visão de Futuro | Cidadania e Reconhecimento.

Fase 3 - 2015 | Grupos produtivos analisados: Artesanato Cana-Brava Papel L Mais - Pontas de Pedras/Goiana e ASAS - Associação dos Artesãos Solidários de São José da Cora Grande, com a distinção de trabalhar com matérias-primas recicláveis resíduos de papelão e caixa de ovos e resíduos da fabricação de capachos em fibra de coco; estes grupos tiveram reconhecimento do Prêmio Top100 SEBRAE de Artesanato e Talentos do Brasil Rural, além de ter apoio do Laboratório O Imaginário e do Centro Pernambucano de Design. Esta fase da pesquisa ampliou os conteúdos dos protocolos com a apropriação dos conceitos: Redes, diversidade e proposta única de vendas. 
Por meio da interlocução de diversas fontes bibliográficas, do trabalho coletivo do grupo de especialistas e das contribuições relevantes dos membros das seis comunidades produtivas, foi construído um modelo, que foi avaliado e testado nas práxis comunitárias. Foram definidas as seguintes dimensões: Sustentabilidade: Econômica, Social, Ambiental, Cultural; Fluxos e Contra-Fluxos: Produtos, Recursos, Informações, Conhecimentos; Circuito da Cultura: Produção, Identidade, Regulação, Representação, Consumo.

A pesquisa foi estruturada em três etapas para cada fase do projeto:

Preparação, englobando a identificação de dados da localidade e do grupo produtivo; pesquisa bibliográfica; entrevistas com pessoas associadas ao grupo; e entrevistas com especialistas. Vivências, com visitas a campo; encontro coletivo com os artesãos; resgate da memória oral do grupo; coleta de documentos; e identificação de marcos históricos. E por fim, a Sistematização, com a indexação da documentação coletada, compilação dos protocolos construídos, apresentação e validação dos resultados da pesquisa; e a entrega final do relatório de pesquisa.

A análise da cadeia produtiva foi baseada em observações e registros sistemáticos das práticas, valores, saberes e fazeres. Com a rica vivência da pesquisa foram encontrados na cadeia: Obstruções/gargalos, vazios/espaços por ocupar, dessincronias, retrabalhos, transpassos/overlappings, desinformação, não linearidade, os sistemas de apoio e o entorno político, cultural, ambiental, social, econômico e institucional.

As dinâmicas estabelecidas nos diferentes ciclos da cadeia produtiva do setor criativo foram tratadas pela abordagem da economia criativa em que um ato (criativo) gerador de valor simbólico é o elemento central da formação do valor agregado e da consequente atribuição de preço, o que resulta em riqueza cultural e econômica.

Uma abordagem prática baseada no cotidiano dos atores sociais envolvidos na cadeia de criação/produção/distribuição/disseminação (difusão)/consumo (fruição) dos artefatos culturais observando, analisando e registrando as suas práticas, valores, saberes e fazeres.

O pressuposto foi a imersão na disciplina ou interdisciplina dos estudos culturais em que se assume o importante papel da comunicação ${ }^{3}$ na produção da cultura na contemporaneidade ${ }^{4}$ em uma rede de complexas relações sociais ${ }^{5}$ (TABOSA et al, 2015).

A pesquisa que buscou em fases anuais e em etapas subsequentes construir um modelo de análise para a produção cultural artesanal com potencial de uso em diversas tipologias e em territórios produtivos distintos foi um desafio para a equipe de pesquisadores, principalmente por se tratar de fenômenos sociais como o artesanato que na visão de (Gullar, 2000) está entre as primeiras formas de ação do homem sobre o meio ambiente e sobre si mesmo, já que o homem não nasce humano, ele se torna humano, pelo trabalho e pela inteligência.

\footnotetext{
${ }^{3}$ Comunicação entendida como uma coprodução de significados no ambiente das intersubjetividades

${ }^{4}$ Cultura como um modo de organização de significados e valores de uma determinada sociedade onde uma rede de atores sociais em diferentes posições de poder e em disputa de interesses tentam impor seus significados sobre os demais.

${ }^{5}$ Produção, mercado, construção de Identidades, regulações, representações, diversidade etc.
} 
Nesse contexto a sistematização ${ }^{6}$ das observações e das experiências vivenciadas em protocolos é um elemento chave para lograr uma evolução contínua da captura de conhecimentos em um campo onde convivem e trabalham em conjunto pessoas com conhecimentos tácito e científico.

Foram definidos quatro protocolos para análise da cadeia de artesanato: matérias-primas, processos produtivos; acesso a mercados e visão de futuro (cidadania e reconhecimento) que consolidam os elementos chaves para o registro das observações e experiências com posterior identificação das oportunidades de melhorias e dos diferenciais competitivos da cadeia.

A Figura 1 apresenta a representação tridimensional dos elementos utilizados na visualização das oportunidades de melhoria e nos diferenciais competitivos da cadeia produtiva do artesanato.

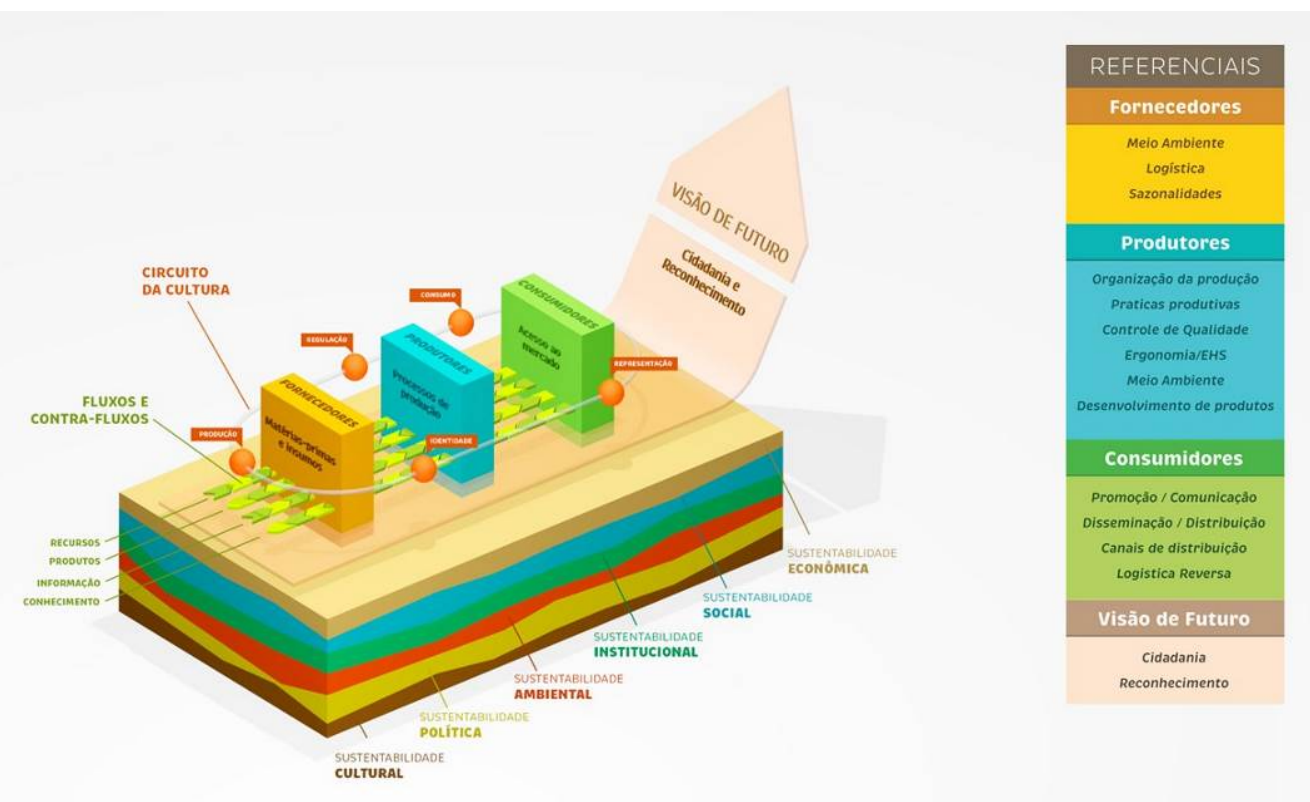

Figura 1 - Representação gráfica do modelo de cadeia produtiva utilizado Fonte: Elaborado pelos autores com base na Pesquisa realizada.

\subsection{Metodologia}

A metodologia de abordagem adotada para a pesquisa foi a dialética, considerada uma das metodologias mais convenientes para o estudo da realidade social, pois fornece as bases para uma interpretação mais dinâmica e totalizante da realidade (DEMO, 1995). Como método de procedimento foi utilizado o método comparativo, frequentemente utilizado em estudos de largo alcance - um dos traços característicos deste trabalho e que busca ressaltar similaridades e diferenças entre fenômenos (Gil,1989). Já o Estudo de Caso foi aplicado porque se trata de um fenômeno associado a eventos contemporâneos e se caracteriza pela capacidade de lidar com uma completa variedade de evidências - documentos, artefatos, entrevistas e observações (YIN, 2001).

\footnotetext{
${ }^{6}$ Segundo (HOLLIDAY, 2006) a sistematização é aquela interpretação crítica de uma ou várias experiências que, a partir de seu ordenamento e reconstrução, descobre ou explicita a lógica do processo vivido, os fatores que intervieram no dito processo, como se relacionaram entre si e porque o fizeram desse modo.
} 
Para condução de pesquisa, foram definidas as seguintes estratégias metodológicas: Levantamento de dados relativos à produção, circulação e consumo nas comunidades estudadas; Análise dos modelos das cadeias produtivas culturais (cinema, música, vídeo e TV, indústria criativa do Recife, carnaval do Rio de Janeiro) e outras cadeias produtivas (confecções, gesso e moveleira) (PRESTES FILHO, 2007, 2009a, 2009b); (NAGI-PE, 2012); $\operatorname{CGEE~(2011,~2012).~A~seguir~a~}$ pesquisa bibliográfica e documental, entrevistas semiestruturadas, road maps e focus groups com lideranças comunitárias e especialistas em design e artesanato na busca do entendimento da cadeia produtiva cultural do artesanato, e finalmente, a sistematização da experiência visando à construção de um conjunto de protocolos aplicáveis as comunidades produtoras.

\subsection{Referencial teórico}

A seguir são apresentados alguns conceitos fundamentais para o entendimento da cadeia produtiva conforme explorado neste artigo.

\subsubsection{Cadeia de valor e design}

Na sua visão tradicional, uma cadeia produtiva é um conjunto de etapas consecutivas ao longo das quais os diversos insumos sofrem algum tipo de transformação até a constituição de um produto final e sua colocação no mercado.

A Association Française de Normalisation - AFNOR (2012) adota um conceito mais amplo, considerando a cadeia produtiva como um encadeamento de modificações da matéria-prima, com finalidade econômica, que inclui desde sua exploração no meio ambiente natural até o seu retorno à natureza, passando pelos circuitos produtivos, de consumo, de recuperação, tratamento e eliminação de efluentes e resíduos sólidos.

KRUCKEN (2009) propõe uma reflexão sobre design e cadeia de valor baseados na promoção de produtos locais. A proposta sugere uma atuação do designer ao longo de toda a cadeia produtiva e incorpora atributos emocionais e psicológicos aos estéticos-formais, tradicionalmente reconhecidos na prática do design. A autora também chama atenção dos designers para a percepção de agregação de valor a partir do reconhecimento dos conceitos de terroir ${ }^{7}$ e certificação de origem ${ }^{8}$, principalmente para referenciar comunidades e de seus territórios

\subsubsection{Os estudos culturais e o circuito da cultura}

Os estudos culturais, que tiveram origem na Inglaterra dos anos 1950, definiram cultura como a organização dos significados e dos valores de determinados grupos sociais que, em posições diferenciais de poder político, financeiro ou de acesso à mídia, lutam pela imposição de suas culturas à sociedade mais ampla (HALL, 2009). Um produto deliberado da mão-de- obra humana é um

\footnotetext{
${ }^{5}$ Conceito de terroir "é o espaço geográfico no qual os valores patrimoniais são frutos de relações complexas de características culturais, sociais, ecológicas e econômicas tecidas ao longo do tempo" (Brodhag, 2000, apud Krucken 2009). Autores atribuem ao conceito de terroir à valorização do capital simbólico.

${ }^{8}$ Certificação de origem "é o documento que serve como comprovação da origem da mercadoria e habilitação à isenção ou redução do imposto de importação". http://www.ibsolutions.com.br/doc-impexp/certificado-de-origem
} 
artefato cultural na medida em que vem sendo construído através de um percurso de sentidos e práticas sociais.

O circuito da cultura é uma forma forma articulada de ver o artefato artesanal, na análise do processo da PRODUÇÃO, quando envolve a compreensão da cultura, das formas de vida, através e dentro das quais o produto é criado; o processo do CONSUMO, incluindo as dimensões sociais e simbólicas; a IDENTIDADE ou as identidades culturais dos artefatos artesanais, considerando a visão histórica em que o passado é reconstituído num processo de contínua reinterpretação; a REPRESENTAÇÃO como uma prática social importante dentro do processo de construção e troca de significados entre os membros de uma sociedade; a REGULAÇÃO, que pode variar, a depender do contexto da análise das oportunidades de comercialização, como em premiações e concursos nacionais caso do Top 100 Brasil do SEBRAE ou o recente Vitrines Culturais da Copa 2014 promovido pelo MinC Brasil (Du GAY, 1997).

\subsubsection{As sustentabilidades}

O campo das sustentabilidades pode ser entendido a partir de quatro dimensões (DEHEINZELIN, 2010), relatando as relações sociais estabelecidas na cadeia de pré-produção, produção, distribuição, comunicação e consumo: Econômica - através da formação e expansão dos mercados, buscando o economicamente justo; Social - através do fortalecimento das redes e dos laços sociais, buscando o socialmente inclusivo; Ambiental - através do aproveitamento máximo das matérias-primas, reciclagem e reaproveitamento, buscando o ambientalmente respeitoso; Cultural - através da geração e troca de conhecimentos e habilidades que se acumulam e se transmitem, buscando o culturalmente diverso.

\subsubsection{Os fluxos e os contra-fluxos}

Nas visões mais tradicionais e com base na teoria dos sistemas ainda prevalece à linearidade de movimento e sentido único de fluxo com emissor, mensagem e receptor implicando em passividade na recepção ao longo das cadeias produtivas. Esta limitação considera os diferentes aparatos ao longo da cadeia como independentes e impossibilitados ou desmotivados para serem proativos na defesa de seus interesses individuais ou coletivos (Hall, 2009), o que pode comprometer toda a efetividade do planejamento da cadeia.

\subsection{Aplicação do modelo de análise a cadeia produtiva do grupo de ceramistas do Cabo de Santo Agostinho/PE.}

Visando ilustrar a utilização dos protocolos desenvolvidos, será apresentado a seguir uma aplicação ao grupo produtivo ceramistas do Cabo de Santo Agostinho.

\subsubsection{O contexto}

Geograficamente, o Cabo de Santo Agostinho está localizado na região metropolitana do Recife a $33 \mathrm{~km}$ da capital de Pernambuco e com uma população de 169.229 habitantes, segundo dados do (IBGE,2010). A história da produção utilitária em cerâmica no Cabo de Santo Agostinho remonta aos tempos da 
colonização. Durante séculos, as olarias de propriedade dos engenhos produziram apenas tijolos e telhas para atender, exclusivamente, às necessidades da principal atividade econômica da zona da mata sul de Pernambuco. Com o passar do tempo, as olarias começaram a confeccionar moringas, jarras, panelas, potes, alguidar e o prato de curau. Nos anos 70, com a introdução de novas tintas e vernizes, a produção da cerâmica utilitária artesanal teve um crescimento significativo que decresceu no início dos anos 90. Em 2003, foram iniciadas as ações do Laboratório de Pesquisa e Design 0 Imaginário ${ }^{9}$ com o estímulo ao desenvolvimento de novos produtos, a participação de feiras, a reorganização do processo produtivo cerâmico com implementação de novos equipamentos na etapa de beneficiamento, modelagem e queima possibilitando o controle do processo e a vitrificação das peças cerâmicas ${ }^{10}$. Em 2007, uma parceria com a Prefeitura do Cabo permitiu a construção de um novo local de produção e foi formatado um projeto de um forno a gás natural, em parceria com o Banco do Nordeste do Brasil, de patamares de queima de até $1200^{\circ} \mathrm{C}$, instalado em área com disponibilidade da passagem da tubulação de gás da Companhia Pernambucana de Gás. O novo espaço de produção é atualmente o Centro de Artesanato do Cabo - Arquiteto Wilson Campos Júnior, que está localizado às margens da $\mathrm{PE}-60$, rota turística para o litoral sul do Estado de Pernambuco.

\subsubsection{A construção dos protocolos analíticos}

Como uma das entregas mais importantes da análise da cadeia produtiva, é possível observar nos Quadros 1 a 4, um recorte do que foi apurado nos quatro protocolos analíticos (matérias-primas, processos produtivos, acesso a mercado e visão de futuro) para a Cerâmica do Cabo de Santo Agostinho. Nos quadros existe uma sinalização em verde para os diferenciais competitivos do grupo de ceramistas, e em vermelho, para as mais urgentes oportunidades de melhoria da produção cerâmica artesanal do grupo.

\footnotetext{
${ }^{9}$ O Laboratório de Pesquisa e Design O Imaginário está vinculado aos departamentos de design e de cultura da Universidade Federal de Pernambuco - UFPE composto por profissionais, professores e estudantes de diversas áreas do conhecimento, que atuam com foco no design como instrumento a serviço da sustentabilidade, ambiental, econômica e social.

10 Em 2006, o Imaginário iniciou os testes com esmaltes naturais, isentos de chumbo, visando ampliar o mercado e agregar valor aos produtos e incorporar a etapa ao processo atual de produção cerâmica do Cabo. (ANDRADE e CAVALCANTI, 2006); (TABOSA et al, 2007).
} 
Quadro 1 - Recorte do Protocolo de análise da cadeia produtiva - Matérias-primas

\begin{tabular}{|l|l|l|l|}
\hline Dimensões & ASPECTOS & Jazida & Refugo Industrial \\
\hline \multirow{2}{*}{$\begin{array}{l}\text { SUSTENTABILIDADE } \\
\text { AMBIENTAL }\end{array}$} & Fontes & Suape & Roca \\
\cline { 2 - 4 } & Forma De Extração & Manual & Mecanizada \\
\cline { 2 - 4 } & $\begin{array}{l}\text { Impactos Ao Meio } \\
\text { Ambiente }\end{array}$ & $\begin{array}{l}\text { Negativo pela extração } \\
\text { não-planejada }\end{array}$ & $\begin{array}{l}\text { Positivo, pois evita o } \\
\text { descarte inadequado } \\
\text { deste refugo }\end{array}$ \\
\hline ECONTENTABILIDADE & Período de acesso & $\begin{array}{l}\text { Inacessível no período } \\
\text { chuvoso }\end{array}$ & Indiferente \\
\hline REGULAÇÃO & Riscos à disponibilidade & $\begin{array}{l}\text { Fechamento da jazida } \\
\text { pela administração e/ou } \\
\text { esgotamento da jazida }\end{array}$ & $\begin{array}{l}\text { Pequeno - carta de } \\
\text { intenção com garantia } \\
\text { de cessão de 2 } \\
\text { toneladas/mês (2 anos) }\end{array}$ \\
\hline
\end{tabular}

Fonte: Elaborado pelos autores, com base na pesquisa realizada

Quadro 2 - Recorte do Protocolo de Identificação de Processos Produtivos

\begin{tabular}{|l|l|l|l|}
\hline Dimensões & ASPECTOS & Torno & Colagem \\
\hline $\begin{array}{l}\text { SUSTENTABILIDADE } \\
\text { ECONÔMICA }\end{array}$ & Controle de qualidade & Existe - reflete na imagem do grupo de ceramistas \\
\hline $\begin{array}{l}\text { AUSTENTABILIDADE } \\
\text { SUSTENTABILIDADE } \\
\text { SOCIAL }\end{array}$ & Rejeito & Alta geração de peças quebradas \\
\hline \multirow{2}{*}{$\begin{array}{l}\text { SUSTENTABILIDADE } \\
\text { ECONÔMICA }\end{array}$} & $\begin{array}{l}\text { Desenvolvimento de } \\
\text { produtos }\end{array}$ & $\begin{array}{l}\text { Grupo diverso em gênero, etnia, orientação } \\
\text { religiosa e de gênero, etária e com inclusão de } \\
\text { pessoas com necessidades especiais }\end{array}$ \\
\cline { 2 - 3 } & Limitantes do processo & $\begin{array}{l}\text { Oriatividade própria } \\
\text { Sugestões de clientes }\end{array}$ \\
\hline
\end{tabular}

Fonte: Elaborado pelos autores, com base na pesquisa realizada

Quadro 3 - Recorte do Protocolo de Identificação de Acesso a Mercados

\begin{tabular}{|l|l|l|}
\hline Dimensões & ASPECTOS & Grupo Cerâmica do Cabo \\
\hline $\begin{array}{l}\text { FLUXO DE } \\
\text { INFORMAÇÃo }\end{array}$ & $\begin{array}{l}\text { Facilitadores de acesso } \\
\text { a mercado }\end{array}$ & $\begin{array}{l}\text { Designers, arquitetos e decoradores; Laboratório O } \\
\text { Imaginário, Sebrae }\end{array}$ \\
\hline \multirow{2}{*}{$\begin{array}{l}\text { SUSTENTABILIDADE } \\
\text { ECONÔMICA }\end{array}$} & Fixação de preço & $\begin{array}{l}\text { Tabela de Cálculo mão de obra, matéria-prima, } \\
\text { insumos e margem de lucro }\end{array}$ \\
\cline { 2 - 3 } & $\begin{array}{l}\text { Comercialização de } \\
\text { propriedade criativa }\end{array}$ & $\begin{array}{l}\text { Realização de cursos, demonstrações e oficinas de } \\
\text { repasse das técnicas cerâmicas }\end{array}$ \\
\cline { 2 - 3 } & Material de suporte & Marca, folder, banner, catalogo, embalagem \\
\cline { 2 - 3 } & $\begin{array}{l}\text { Proposta de Venda } \\
\text { Única }\end{array}$ & $\begin{array}{l}\text { Expografia, etiqueta, catálogos, vídeo, presença } \\
\text { nas redes sociais, discurso de representante em } \\
\text { eventos }\end{array}$ \\
\hline \multirow{2}{*}{ REGULAÇÃO } & Prêmios & $\begin{array}{l}\text { Top 100 Sebrae de Artesanato em 2009 e 2012; } \\
\text { Bienal de Design; Prêmio Objeto Brasileiro; Vitrines } \\
\text { Culturais }\end{array}$ \\
\hline
\end{tabular}

Fonte: Elaborado pelos autores, com base na pesquisa realizada 
Quadro 4 - Recorte do Protocolo de Identificação de Cidadania e Reconhecimento

\begin{tabular}{|l|l|l|}
\hline Dimensões & ASPECTOS & Grupo Cerâmica do Cabo \\
\hline $\begin{array}{l}\text { SUSTENTABILIDADE } \\
\text { ECONÔMICA }\end{array}$ & Prosperidade & $\begin{array}{l}\text { Sustentável pela gestão e participação dos } \\
\text { membros do grupo }\end{array}$ \\
\hline \multirow{2}{*}{$\begin{array}{l}\text { SUSTENTABILIDADE } \\
\text { INSTITUCIONAL }\end{array}$} & $\begin{array}{l}\text { Nível de } \\
\text { Institucionalização }\end{array}$ & $\begin{array}{l}\text { Grupo juridicamente não formatado. } \\
\text { Representação através de MEI - } \\
\text { Microempreendedores Individuais }\end{array}$ \\
\cline { 2 - 3 } & $\begin{array}{l}\text { Planejamento } \\
\text { estratégico }\end{array}$ & Formatado e em execução \\
\cline { 2 - 3 } Slano de negócios & Formatado e em execução \\
\cline { 2 - 3 } $\begin{array}{l}\text { SUSTENTABILIDADE } \\
\text { SOCIAL }\end{array}$ & $\begin{array}{l}\text { Percepção de causa } \\
\text { comum }\end{array}$ & $\begin{array}{l}\text { Opção de ocupação e renda, com retorno } \\
\text { financeiro e de visibilidade para o grupo }\end{array}$ \\
\cline { 2 - 3 } & Celebrações & $\begin{array}{l}\text { Ações de treinamento e confraternizações ao } \\
\text { término de eventos importantes e no fim de ano }\end{array}$ \\
\hline
\end{tabular}

Fonte: Elaborado pelos autores, com base na pesquisa realizada

\subsubsection{Contribuições da pesquisa}

As principais contribuições da Pesquisa para os grupos produtores de artesanato envolvidos diretamente na investigação são as seguintes:

- Identificação de áreas de oportunidades de melhorias e reforço dos diferenciais competitivos;

- Apoderamento do uso dos protocolos pelo fato de terem sido desenvolvidos em conjunto com os pesquisadores;

- Recuperação da memória histórica do grupo, reforço dos laços sociais entre os integrantes e subsidio para a elaboração dos discursos para vendas com valor agregado.

- Disponibilização de um dossiê de informações sobre o grupo produtivo e o contexto onde atua para uso imediato na elaboração de projetos e pleitos dirigidos a potenciais financiadores ou apoiadores.

Para os demais artesãos, a pesquisa apresenta a capacidade de replicabilidade do Modelo Analítico para outras tipologias produtivas e/ou territórios.

\section{CONCLUSÃO}

No mundo da cultura, assumimos que um produto deliberado da mão-deobra humana é um artefato cultural na medida em que vem sendo construído através de um percurso de sentidos e práticas sociais. $O$ artefato artesanal tornase um artefato cultural pelo processo de produção, circulação, disseminação, distribuição e consumo quando são articulados para formar uma unidade temporária de análise, pois as necessidades e os desejos são fluídos e inconstantes na modernidade (Du GAY, 1997); (BAUMAN, 2001)

Essa visão da cadeia produtiva para o artesanato rompe com o paradigma de que o consumo ou quaisquer outras etapas dessa cadeia é determinado de forma linear e unidirecional pela produção. Neste contexto foi analisada a cadeia produtiva do artesanato com seus fluxos e contra-fluxos, econômicos (tangíveis) e simbólicos (intangíveis), seus diversos enfoques da sustentabilidade e consideradas as 
interferências a que está sujeita. Ao explicitar os aspectos subjetivos, até então submergidos nas análises das cadeias produtivas tradicionais, transpõe-se uma nova ponte na busca de conhecimento aplicado.

O grande desafio foi a complexidade do tema com pouca ou nenhuma cobertura bibliográfica específica. Diante de sua singularidade, é um tema de pesquisa que merece receber etapas de seguimento, construindo e validando novos enfoques e visões em conjunto com outros grupos produtivos. Para este artigo foi feita a descrição da análise da cadeia produtiva dos Ceramistas do Cabo de Santo Agostinho, que serviu para ilustrar a aplicação dos protocolos estabelecidos na pesquisa. A experimentação do modelo proposto indica sua potencialidade para ser utilizado em outras comunidades artesãs com outras tipologias produtivas e em outros territórios.

Nesse contexto a sistematização das observações e das experiências vivenciadas foi um elemento chave para lograr a evolução contínua da captura de conhecimentos em um campo onde convivem e trabalham em conjunto pessoas com conhecimentos tácito e científico.

Como mais um instrumento de suporte a produção artesanal, os resultados da pesquisa podem orientar políticas públicas com vistas a promover a qualidade de vida dos artesãos, gerando emprego e renda estáveis que viabilizem a retenção dos jovens neste ambiente produtivo.

\section{REFERÊNCIAS}

AFNOR. Association Française de Normalisation. Normatization Terms. Disponível na internet em: <www.afnor.org/en>. Acesso em 12 abr. 2012

ANDRADE, Ana; CAVALCANTI, Virginia. Imaginário pernambucano: design, cultura, inclusão social e desenvolvimento sustentável. Recife: Zoludesign, 2006.

BAUMAM, Zygmund. Modernidade Líquida. Rio de Janeiro: Zahar,2001 BONSIEPE.

CGEE - Centro de Gestão e Estudos Estratégicos. Oportunidades de negócios para o município de Recife (PE). Série Documentos Técnicos, Recife: CGEE, 2011

CGEE - Centro de Gestão e Estudos Estratégicos. Inovações tecnológicas em cadeias produtivas selecionadas. Série Documentos Técnicos, Recife: CGEE, 2012

DEHEINZELIN, Lala. Creative economy for development: a new model leading to sustainability and better futures. Personal working paper, 2010.

DEMO, Pedro. Introdução à metodologia da ciência. São Paulo: Atlas, 1995.

Du GAY, Paul. Doing Cultural Studies: The story of the Sony Walkman. The Open University. London: SAGE Publications, 1997

GULLAR, Ferreira. Poesia primeira. In Artesanato do Brasil. Brasília: Reflexo Design/SEBRAE, 2001.

GIL, Antônio Carlos. Métodos e técnicas de pesquisa social.São Paulo: Atlas,1987.

HALL, Stuart Metáforas de Transformação. In Da diáspora: identidades e mediações culturais. SOVIK, Liv. (Org.). Belo Horizonte: Editora UFMG, 2009.

HOLLIDAY, Oscar. Para sistematizar experiências. João Pessoa: Editora da UFPB, 1996 
HOWKINS, John. The Creative economy: how people make money from ideas. London/Uk: Penguin Books Group, 2001.

IBGE Instituto Brasileiro de Geografia e Estatística. Censo demográfico 2010. Brasília: IBGE, 2010 KOTLER, Philip. Princípios de marketing. Rio de Janeiro: Prentice-Hall, 2004.

KRUCKEN, Lia. Design e território: valorização de identidades e produtos locais. São Paulo: Nobel, 2009.

NAGI-PE. Indústria Criativa: Mapeamento dos Gargalos Setoriais. Recife: Portodigital, 2012

PRESTES FILHO, Luiz Carlos (Org). Cadeia Produtiva da Economia da Música. Rio de Janeiro: Epapers,2007

PRESTES FILHO, Luiz Carlos (Org). Cadeia Produtiva da Economia do Carnaval. Rio de Janeiro: Epapers, 2009a

PRESTES FILHO, Luiz Carlos. Cadeia Produtiva da Economia do Carnaval. In CRIBARI, Ana Isabela (Org) Economia da Cultura. Recife: FUNDAJ/Editora Massangana, 2009b.

SEBRAE NACIONAL. Relatório premiação Top 100 SEBRAE 2012. Brasília: SEBRAE, 2013.

UNCTAD/ONU.Creative economy report. Berne/Suisse: UNCTAD, 2010.

UNESCO. La artesania y el mercado internacional: comercio y codificación aduaneira. Manila/Filipinas: Unesco/CCl, 1999.

TABOSA, Tibério at al. Empreendedorismo social transformador: o caso da ação do Projeto Imaginário Pernambucano na comunidade artesanal do Cabo de Santo Agostinho/PE - Anais do XXI EnANPAD - Encontro Nacional de Pesquisas em Administração. Rio de Janeiro/RJ, 2006.

TABOSA, Tibério. Creando una Propuesta de Valor para los Consumidores Conscientes: Productos Artesanales Solidários de Raiz y Alma.Revista Artesanias de América editada pelo CIDAP - Centro Interamericano de Artesanias y Artes Populares / OEA - Organização dos Estados Americanos n. 63-64, julho de 2007 TABOSA, Tibério. A visão ampliada do artefato artesanal na ótica do circuito da cultura e suas implicações na comercialização. In CUNHA, Gabriel. Artesanato questões de comercialização. Coimbra, Portugal: CEARTE, 2011.

TABOSA, Tibério; CAVALCANTI, Virgínia. Uma contribuição teórica para a estratégia de marketing de produtos culturais: o caso da produção, circulação e consumo de objetos artesanais de valor agregado Anais do o VIII Congresso Nacional de Excelência em Gestão, Rio de Janeiro, 2012.

TABOSA, Tibério et al. Diseño Social y cadena productiva de la artesanía: un análisis sobre la cerâmica do Cabo de Santo Agostinho PE -Brasil. Anales del VIII Congresso Internacional de Diseño de la Habana - FORMA 2015 “Diseño con Sentido". La Habana, Cuba, junio 2015.

YIN, Robert. Estudo de caso: planejamento e métodos. Porto Alegre: Bookman, 2001. 